\section{Bradykinin and noradrenaline preconditioning influences level of antioxidant enzymes SOD, CuZn-SOD, Mn-SOD and catalase in the white matter of spinal cord in rabbits after ischemia/reperfusion}

\author{
Marianna Danková, \\ Iveta Domoráková, ${ }^{1}$ Zuzana Fagová, ${ }^{1}$ \\ Milan Stebnický, ${ }^{2,3}$ Alexandra Kunová, ${ }^{1}$ \\ Eva Mechírová \\ ${ }^{1}$ Department of Histology and \\ Embryology, Pavol Jozef Šafárik \\ University, Košice \\ ${ }^{2} 2^{\text {nd }}$ Department of Surgery, Pavol Jozef \\ Šafárik University, Košice \\ ${ }^{3}$ Louis Pasteur University Hospital, \\ Košice, Slovak Republic
}

\section{Abstract}

The aim of present work is to assess the effects of bradykinin $(\mathrm{Br})$ or noradrenaline (Nor) preconditioning to the levels of antioxidant enzymes: superoxide dismutase (SOD), copper, zinc superoxide dismutase (CuZn-SOD), manganese superoxide dismutase (Mn-SOD) and catalase in ischemia/reperfusion (I/R) model in the rabbit spinal cord white matter as well as effect on glial fibrillary acidic protein (GFAP) and ubiquitin immunoreaction in glial cells. Rabbits were preconditioned by intraperitoneal single dose of $\mathrm{Br}$ or Nor $48 \mathrm{~h}$ prior to $20 \mathrm{~min}$ of ischemia followed by 24 or $48 \mathrm{~h}$ of reperfusion. White matter of $\mathrm{L}_{3}-\mathrm{L}_{6}$ spinal cord segments was used for comparison of antioxidant enzyme levels in sham control, ischemic groups and four preconditioned groups. The total SOD level in the Br or Nor preconditioned groups after $48 \mathrm{~h}$ of reperfusion was increased vs $\mathrm{Br}$ or Nor preconditioned groups after $24 \mathrm{~h}$ of reperfusion. The comparison among the ischemic group $v s$ $\mathrm{Br}$ preconditioned $(\mathrm{P}<0.05)$, and Nor preconditioned $(\mathrm{P}<0.001)$ groups after $48 \mathrm{~h}$ of reperfusion, showed statistically significant decrease of Mn-SOD activity. Tissue catalase level activity was significantly decreased in the $\mathrm{Br}$ preconditioned group after $48 \mathrm{~h}$ of reperfusion $(\mathrm{P}<0.05)$ and Nor preconditioned groups after $24 \mathrm{~h}$ of reperfusion $(\mathrm{P}<0.001)$ and also after $48 \mathrm{~h}$ of reperfusion $(\mathrm{P}<0.001)$, in comparison to ischemic group after $48 \mathrm{~h}$ of reperfusion. Significantly decreased tissue catalase activity $(\mathrm{P}<0.05)$ in both Nor preconditioned groups after 24 or $48 \mathrm{~h}$ of reperfusion was measured $v s \mathrm{Br}$ preconditioned group after $48 \mathrm{~h}$ of reperfusion. According to our results, in the white matter, activation of stress proteins in glial cells, as well as antioxidant enzymes levels, were influenced by pharmacological preconditioning followed by $20 \mathrm{~min}$ of ischemia and 24 or $48 \mathrm{~h}$ of reperfusion. These changes contribute to ischemic tolerance acquisition and tissue protection from oxidative stress during reperfusion period.

\section{Introduction}

Ischemia and reperfusion not only induce histopathological changes in the grey matter but also influence reaction of white matter glial cells in the spinal cord. Existing studies indicate that the preconditioning is a possible way to protect nerve and neuroglial cells and can result in ischemic tolerance of cells. ${ }^{1,2}$ Ischemic tolerance represents the ability of tissues and cells to respond to sublethal stimuli by building of extremely powerful endogenous protection allowing them to survive otherwise lethal ischemic injury. The tolerance to the ischemic damage can be induced by ischemia or by other stress stimuli. ${ }^{3,4}$ On the basis of our previous published results ${ }^{5}$ involved in changes in the spinal cord grey matter, the aim of this study is focused on study of spinal cord white matter. White matter contains axons and glia, including astrocytes, oligodendrocytes, and microglia, without any neuronal cell bodies, dendrites or conventional synapses. ${ }^{6}$ Protoplasmic and fibrillary astrocytes contain filamentous proteins vimentin and glial fibrillary acidic protein (GFAP) in their cytoplasm. These intermediate filaments are highly expressed in the white matter compared to grey matter, ${ }^{7}$ suggesting their specialized function in maintenance of myelin and remyelination in pathologic conditions. White matter astrocytes have higher capacity for metabolism of glutamate to glutamine than grey matter astrocytes. ${ }^{8}$ Overload of glutamate may cause excitotoxicity in oligodendrocytes, suggesting that glutamate clearance by astrocytes in the white matter protects oligodendrocytes. In addition, astrocytes are capable to detoxify reactive oxygen and nitrogen species, by induction of glutathione, thioredoxin system and superoxide dismutase (SOD) in response to oxidative stress. ${ }^{9}$ The full complexity and interaction of these pathways is still being explored, however, astrocytes have the capacity to both enhance and undermine the repair process after ischemic injury. ${ }^{10}$ Ischemia and reperfusion induce increased activity of reactive oxygen species (ROS) followed by synthesis of protective antioxidant enzymes. ${ }^{11} \mathrm{SOD}$ is an
Correspondence: Eva Mechírová, Department of Histology and Embryology, Faculty of Medicine, Pavol Jozef Šafárik University, Šrobárova 2, 04180 Košice, Slovak Republic. E-mail: eva.mechirova@upjs.sk

Key words: Bradykinin; noradrenaline; preconditioning; rabbit; spinal cord; ischemia; antioxidant enzymes.

Contributions: all the authors contributed equally to the study, made a substantive intellectual contribution, and read and approved the final version of the manuscript.

Acknowledgements: The authors gratefully thank Mrs. Anna Hantke for her exceptional technical assistance. This work was supported by the VEGA grants 1/0348/10, 1/0815/14 and $1 / 0439 / 17$.

Conflict of Interest: the authors declare no conflict of interest.

Received for publication: 10 May 2019.

Accepted for publication: 28 September 2019

This work is licensed under a Creative Commons Attribution-NonCommercial 4.0 International License (CC BY-NC 4.0).

(C) Copyright: the Author(s), 2019

Licensee PAGEPress, Italy

European Journal of Histochemistry 2019; 63:3045 doi:10.4081/ejh.2019.3045

active oxygen free radical scavenger that can efficiently catalyse the dismutation of superoxide anions thus conferring a critical antioxidant response in nearly all cells when they are exposed to oxygen. Catalase is one of the earliest discovered antioxidant enzymes and plays a central role in cellular protection against ROS by catalysing the decomposition of $\mathrm{H}_{2} \mathrm{O}_{2}$ into water and oxygen. Removal of $\mathrm{H}_{2} \mathrm{O}_{2}$ by catalase is important in preventing lipid peroxidation of membranes by hydroxyl radicals. ${ }^{12}$ Bradykinin (Br) is an endogenous nonapeptide, a principal active agent of kallikreinkinin system. It is synthesized locally within tissues during the injury such as ischemia and reperfusion injury. ${ }^{13}$ Except this, $\mathrm{Br}$ is important mediator that has been explored in mediating cardioprotection and neuroprotection in various forms of ischemic conditioning including preconditioning, ${ }^{14}$ postconditioning, ${ }^{15,16}$ and remote ischemic preconditioning. ${ }^{17,18}$ Neuroprotective role of noradrenaline (Nor) postconditioning ${ }^{19}$ and preconditioning ${ }^{20}$ was described in the rat hippocampus. Nor is the principal vasopressor used to restore blood pressure, it triggers the release of glucose and reaches higher levels during stress situations. Nor effects on the spinal cord ischemia and reperfusion are still unknown. 
On the basis of our previous published findings acquired from grey matter, we suppose that application of $\mathrm{Br}$ or Nor as pharmacological preconditioning can impact the level of SOD and catalase also in the white matter of rabbit spinal cord subjected to ischemia and reperfusion. We hypothesize that $\mathrm{Br}$ and Nor preconditioning could trigger activation of astrocytes in the spinal cord white matter, thus contributing to ischemic tolerance acquisition.

\section{Materials and Methods}

The experiments were performed on 62 male New Zealand white rabbits, clinically healthy with a weight of $2.5-3 \mathrm{~kg}$. The animals were bred in the registered animal colony (SK 29004) of the Animal Production Research Centre in Nitra, Slovakia. This study was approved by the Committee for Ethics on Animal Experiments at the Faculty of Medicine, P.J. Šafárik University in Košice, Slovakia. The experimental protocol was approved by the State Veterinary and Food Administration of the Slovak Republic (Ro-1347/15-221, Ro-3524/17-221) in accordance with the European Community Council Directive (86/609/EEC). The rabbits were anesthetized with a mixture of Zoletil 50 (25 $\mathrm{mg} / \mathrm{kg}$, i.m.; Virbac, Carros, France) and Xylazine (15 mg/kg, i.m.; Riemser Arzneimittel AG, Greifswald - Insel Riems, Germany) and operated under sterile conditions. Ischemia of the spinal cord was induced by occlusion of the aorta below the left renal artery for $20 \mathrm{~min} .^{21}$

1. Sham control group $(n=7)$;

2. Ischemic group $-20 \mathrm{~min}$ of ischemia/24 h of reperfusion $(\mathrm{n}=8)$ (20I/24R);

3. Ischemic group -20 min of ischemia/48 h of reperfusion $(n=8)$ (20I/48R);

4. Experimental group $-\mathrm{Br}+20$ min of ischemia/24 h of reperfusion $(n=10)$ (Br/20I/24R);

5. Experimental group $-\mathrm{Br}+20$ min of ischemia/48 $\mathrm{h}$ of reperfusion $(\mathrm{n}=11)$ (Br/20I/48R);

6. Experimental group - Nor +20 min of ischemia/24 h of reperfusion $(n=9)$ (Nor/20I/24R);

7. Experimental group - Nor $+20 \mathrm{~min}$ of ischemia/48 h of reperfusion $(n=9)$ (Nor/20I/48R).

In groups 4 and $5, \mathrm{Br}(150 \mu \mathrm{g} / \mathrm{kg}$, i.p.; Sigma-Aldrich, Steiheim, Germany) was administered intraperitoneally $48 \mathrm{~h}$ before $20 \mathrm{~min}$ of ischemia. Similarly, in groups 6 and 7 Nor was applied intraperitoneally (3.1 $\mu \mathrm{mol} / \mathrm{kg}$, i.p.; hydrogen tartrate salt dis- solved in aqua pro injectione, Noradrenalin, Léčiva, Zentiva, Praha, Czech Republic). After 24 or $48 \mathrm{~h}$ of reperfusion period one part of rabbits were anesthetized and transcardially perfused with $0.9 \%$ saline and $4 \%$ paraformaldehyde in $0.1 \mathrm{M}$ phosphate buffered saline ( $\mathrm{pH}$ 7.4). Spinal cord segments $\mathrm{L}_{3}-\mathrm{L}_{6}$ were embedded to paraffin. The other part of rabbits was designated for biochemical analyses. Fresh, not fixed white matter of $\mathrm{L}_{3}-\mathrm{L}_{6}$ spinal cord segments were removed and immediately cooled in saline and then maintained near $0^{\circ} \mathrm{C}$. Collected tissue from spinal cord white matter was homogenized in a Glass-Teflon homogenizer ( 5 strokes, $\left.800 \mathrm{rpm}, 4^{\circ} \mathrm{C}\right)$ in the extraction medium containing $0.1 \mathrm{M}$ sodium phosphate ( $\mathrm{pH} 7.8)$. Next centrifuged and postmitochondrial supernatant was divided into $100 \mu \mathrm{L}$ aliquots and frozen at $-70^{\circ} \mathrm{C}$ for the enzyme and protein assays. All biochemical assays were performed by a Synergy (TM) 2 Multi-Mode Microplate Reader (BioTek Instruments, Winooski, VT, USA).

\section{Assay of SOD and catalase}

The method used for the SOD assay was a modification of the indirect inhibition assay developed by Sun et al. ${ }^{22}$ The standard assay substrate mixture contained in $200 \mu \mathrm{L}$ : $1 \mathrm{M}$ xanthine, $0.1 \mathrm{M}$ EDTA, $5.6 \times$ $10^{-2} \mathrm{M}$ NBT (p-nitrotetrazolium blue'grade III; Sigma-Aldrich) and 1M BSA, 2mM sodium cyanide in $0.1 \mathrm{M}$ sodium phosphate ( $\mathrm{pH}$ 7.8). The data were assessed as percentage of inhibition $v s$ protein concentration. One unit of SOD was defined as the amount that reduced the absorbance change by $50 \%$ and the results were normalized on the basis of total protein content (U/mg protein). $\mathrm{CuZn-SOD}$ was differentiated from $\mathrm{Mn}$ SOD by addition of $2 \mathrm{mM}$ sodium cyanide to inhibit the activity of CuZn-SOD. CuZnSOD was calculated as the difference between the levels of total SOD and MnSOD as in previous report. The catalase was determined by Goth's spectrophotometric method, ${ }^{23}$ in which the supernatant was incubated with hydrogen peroxide used as the substrate and enzymatic reaction was stopped by the addition of $32 \mathrm{mM}$ ammonium molybdate. The intensity of the yellow complex formed by molybdate and hydrogen peroxide was measured at $450 \mathrm{~nm}$. The level of catalase concentration is given in $\mathrm{U} / \mathrm{mg}$ protein. Total protein concentrations were determined using the method described by Bradford et al. ${ }^{23}$ and analytical grade bovine serum albumin was used to establish a standard curve.

\section{Immunohistochemistry}

The $\mathrm{L}_{3}-\mathrm{L}_{6}$ segments of the spinal cord were dissected and prepared for immuno- histochemistry. Paraffin sections $5 \mu \mathrm{m}$ thick were preincubated with $5 \%$ normal goat serum in $0.1 \mathrm{M}$ PBS (pH 7.4) with $1 \%$ bovine serum albumin for $30 \mathrm{~min}$ at room temperature. Primary polyclonal rabbit antibody against ubiquitin (U 5379, 1:100; Sigma-Aldrich) was mixed in buffered PBS with $1 \%$ normal goat serum and $1 \%$ bovine serum albumin and sections were incubated in this solution overnight at $4^{\circ} \mathrm{C}$. After washing, the ubiquitin sections were incubated with anti-rabbit biotinylated secondary antibody (1:20; Sigma-Aldrich) and next with ExtrAvidin peroxidase (1:20; Sigma-Aldrich). Other sections were incubated with mouse anti-GFAP (MU020-UC Biogenex Lab., San Ramon, CA, USA; $1: 100)$, then incubated at room temperature with biotinylated anti-mouse secondary antibody (1:50; LINK-Biogenex Lab.) and next with streptavidin peroxidase (1:50; LABEL-Biogenex Lab.). Both, ubiquitin and GFAP immunoreactions were visualized using 3, 3'-diaminobenzidine (DAB; Fluka AG, Buchs, Switzerland). Finally, the sections were counterstained with Mayer's hematoxylin and coverslipped with Entellan (Merck, Burlington, MA, USA). For quantitative and qualitative analysis of immunohistochemical methods, light microscope OLYMPUS BX50 equipped with Olympus Camera SP 350 (Olympus, Tokyo, Japan) and QuickPHOTO Industrial 2.3 image analyser software (Promicra, Prague, Czech Republic) were used. The ubiquitin positive glial cells and GFAP positive astrocytes were counted in 10 different randomly selected white matter fields of each spinal cord section. The results obtained by two observers (unaware of the experimental groups) were averaged to obtain the final count for the section. All measurements were done using magnification 200x.

Number of ubiquitin positive glial cells and GFAP positive astrocytes was calculated as the number of cells per unit $\left(100 \mathrm{~mm}^{2}\right)$ of white mater area.

\section{Statistical analysis}

The statistical analysis was performed in GraphPad InStat ver. 3.10 for Windows (GraphPad Software Inc., San Diego, CA, USA). Quantitative evaluation of studied enzymes is expressed as mean \pm SEM. The significance of the differences between experimental groups was analysed using one-way analysis of variance ANOVA test followed by a Tukey-Kramer multiple comparison test. The value of $\mathrm{P}<0.05$ was considered to be statistically significant. 


\section{Results}

Effect of bradykinin and noradrenaline on SOD, Mn-SOD, CuZn-SOD and catalase levels in the white matter of spinal cord in rabbits

The results showed that the total SOD activity was reduced in the ischemic group 2 and in the preconditioned experimental groups 4, 6 in comparison to the total SOD activity in the sham control group 1 . The total SOD activity was increased after $48 \mathrm{~h}$ of reperfusion in the ischemic group 3 and in both preconditioned groups 5 and 7 (Figure 1A). Activity of Mn-SOD in the ischemic groups 2 and 3 was different than in the preconditioned groups 4,5 and 6,7 . In the ischemic group 3, the level of the Mn-SOD activity was increased compared to the group 2. On the contrary, decrease of $\mathrm{Mn}-\mathrm{SOD}$ activity was registered in the preconditioned group 5 compared to the group 4 ; and in the group 7 compared to the group 6 (Figure 1B). The highest level of CuZnSOD activity was registered in the preconditioned group 7 (Figure 1C). Tissue catalase level activity was significantly decreased in the preconditioned groups 5, 6 and 7 in comparison to ischemic group 3 .
Significantly decreased tissue catalase activity in both Nor preconditioned groups 6 and 7 were measured vs $\mathrm{Br}$ preconditioned group 4 (Figure 1D).

\section{GFAP immunohistochemistry}

For detection of astrocytic GFAP in the spinal cord white matter we used immunohistochemical method. The white matter astrocytes in sham control group 1 showed mild GFAP positivity in the thin cytoplasmic processes (Figure $2 \mathrm{~A}$ ). In the ischemic group 2 hypertrophic astrocytic processes surrounded the efferent axons radiating from anterior horns of the grey matter (Figure 2B). In the ischemic group 3 reactive astrocytes with more intensive GFAP positivity were present near the swollen efferent axons (Figure 2C). In both preconditioned groups 4 (Figure 2D) and 6 (Figure $2 \mathrm{~F}$ ) after $24 \mathrm{~h}$ of reperfusion moderate reactive astrocytosis occurred. The cellular processes of reactive astrocytes became thicker and showed stronger GFAP positivity, as well as their cell bodies. In the preconditioned groups 5 (Figure 2E) and 7 (Figure $2 \mathrm{G})$ after $48 \mathrm{~h}$ of reperfusion, prominent reactive astrocytes with intensive GFAP positivity in the hypertrophic cell bodies and processes were observed. Moreover, higher density of GFAP positive astrocytes occurred at the border of grey and white matter in the spinal cord. Quantitative analysis of GFAP positive astrocytes in the spinal cord white matter of all ischemic and preconditioned groups showed significant increase of hypertrophic astrocytes $v s$ sham control group 1. Moreover, in $\mathrm{Br}$ and Nor preconditioned groups (5 and 7) significantly higher number of reactive astrocytes was counted in comparison to ischemic group 3 after $48 \mathrm{~h}$ of reperfusion (Figure $2 \mathrm{H}$ ).

\section{Ubiquitin immunohistochemistry}

Ubiquitin is a stress response protein involved in non-lysosomal degradation of abnormal, unfolded or misfolded proteins. ${ }^{24}$ In the present study, we evaluate ubiquitin distribution in the spinal cord glial cells of the rabbit's white matter.

Twenty min of ischemia followed by 24 or $48 \mathrm{~h}$ of reperfusion caused structural changes in the white matter. Axons and their associated glial cells exhibited structural damage and vacuolization of the white matter. Strong ubiquitin immunoreaction of glial cells was found around ascending and descending axons in the white matter, as well as around the efferent axons radiating from anterior horns. In the cytoplasm of glial cells of ischemic group 2, dark brown aggregates of ubiquitin were visible after
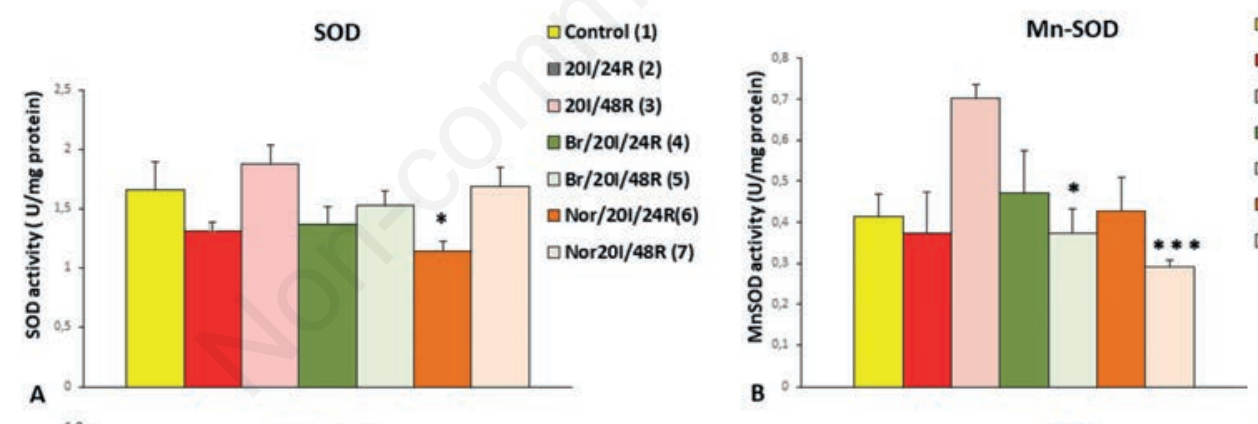

$\square$ Control (1)

- 201/24R (2)

口201/48R (3)

$\triangle \mathrm{Br} / 201 / 24 \mathrm{R}(4)$

$\square \mathrm{Br} / 201 / 48 \mathrm{R}$ (5)

a Nor/201/24R (6)

$\square$ Nor/201/48R (7)

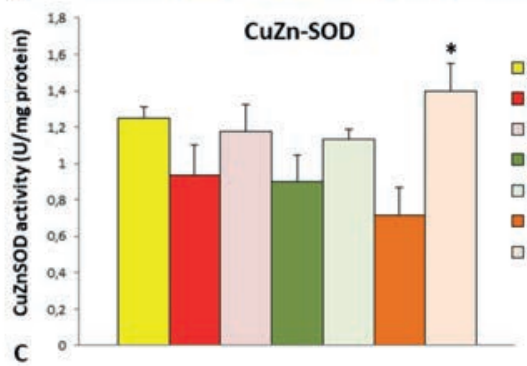

$\square$ Control (1)

- 20I/24R (2)

$\square 201 / 48 R$ (3)

$\triangle \mathrm{Br} / 20 \mathrm{O} / 24 \mathrm{R}(4)$

$\square \mathrm{Br} / 201 / 48 \mathrm{R}$ (5)

$\square \mathrm{Nor} / 201 / 24 \mathrm{R}(6)$

$\square$ Nor/201/48R (7)

들

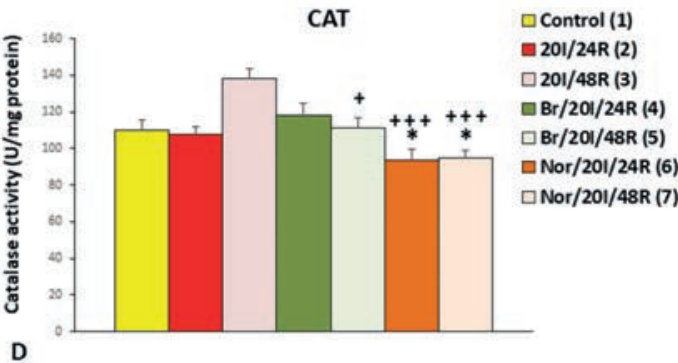

Figure 1. Enzymatic activity of total SOD (A), Mn-SOD (B), CuZn-SOD (C) and catalase (D) in the white matter of L3-L6 spinal cord segments. Significant decrease $\left({ }^{*} \mathrm{P}<0.05\right)$ of the total SOD activity was observed in Nor preconditioned $6 v$ s ischemic group 3 (A). The comparison among the ischemic group $3 v$ s preconditioned groups $5\left({ }^{*} \mathbf{P}<0.05\right)$, and $7(* * * P<0.001)$, showed statistically significant decrease of Mn-SOD activity (B). The increase of the CuZn-SOD level in group 7 was significant $(* \mathrm{P}<0.05)$ compared to the level of CuZn-SOD activity in the group $6(\mathrm{C})$. Tissue catalase level activity was significantly decreased in the preconditioned groups $5(+$ $\mathbf{P}<\mathbf{0 . 0 5}), 6\left({ }^{++} \mathbf{P}<\mathbf{0 . 0 0 1}\right)$ and $7\left(+^{++} \mathbf{P}<\mathbf{0 . 0 0 1}\right)$, in comparison to ischemic group 3 . Significantly decreased tissue catalase activity $\left({ }^{*} \mathbf{P}<0.05\right)$ in both Nor preconditioned groups 6 and 7 were measured $v s$ Br preconditioned group 4 (D). Activity is expressed as international units per milligram of proteins $(\mathrm{U} / \mathrm{mg})$; data are expressed as mean \pm SEM; ANOVA and Tukey-Kramer test were used. 
$24 \mathrm{~h}$ of reperfusion (Figure 3C). Ubiquitin immunoreaction in the cytoplasm of glial cells in ischemic group 3 became more prominent and free, dark brown ubiquitin aggregates were visible in close vicinity of glial cells (Figure 3D). Br preconditioned group 4 (Figure 3A) and Nor preconditioned group 6 showed moderate ubiquitin immunoreaction of cytoplasm and strong ubiquitin positivity in the nucleus of glial cells. Oppositely, in $\mathrm{Br}$ preconditioned group 5 (Figure 3B) and Nor preconditioned group 7 , the glial cells showed no nuclear ubiquitin positivity. On the other hand, cytoplasmic ubiquitin positivity was increased by forming of fine ubiquitin aggregates in the cytoplasm of glial cells. The differences in the number of ubiquitin positive glial cell were evaluated and all significant changes are shown in the graph (Figure 3E).

\section{Discussion}

In oxidative stress, molecular oxygen undergoes incomplete reduction in mitochondria and results in the formation of ROS, which initiate a chain reaction with other molecules to produce new reactive molecules like, superoxide, nitric oxide, and peroxynitrile. ROS either modify the native properties of biomolecules or otherwise make them non-functional. Oxidative stress reflects an imbalance between the production and elimination of ROS. Cellular protection following oxidative stress is provided by antioxidants and antioxidant defence systems. This implies a high probability to increase or decrease the levels of antioxidants and antioxidant enzymes in tissues. ${ }^{25}$ SOD is the key enzyme that causes dismutation of the toxic superoxide radicals into ordinary oxygen molecules and is involved in protection of cells against oxidative damage. According to our results, the level of $\mathrm{Mn}-\mathrm{SOD}$ was considerably increased only
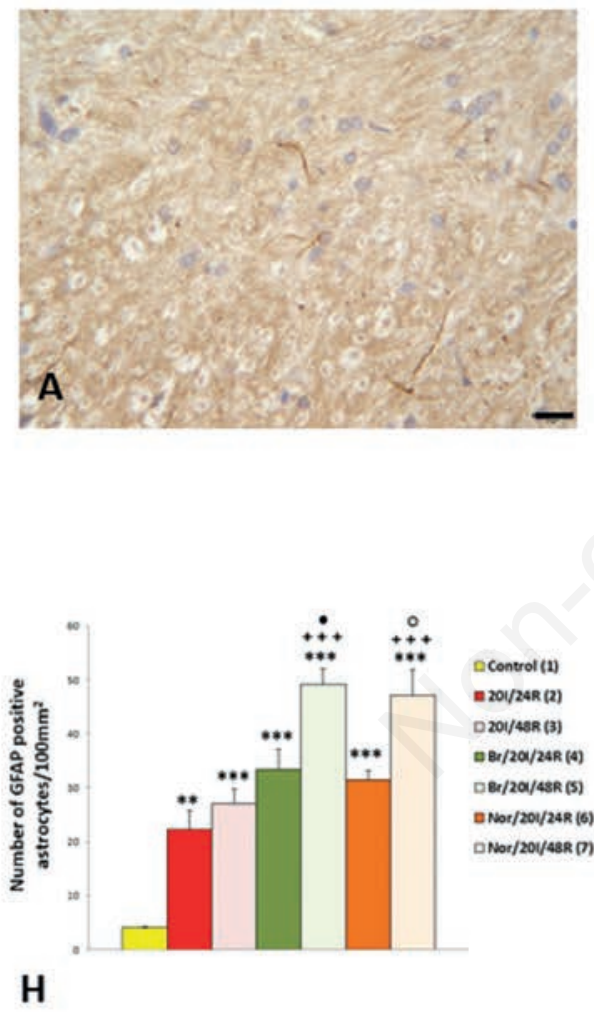
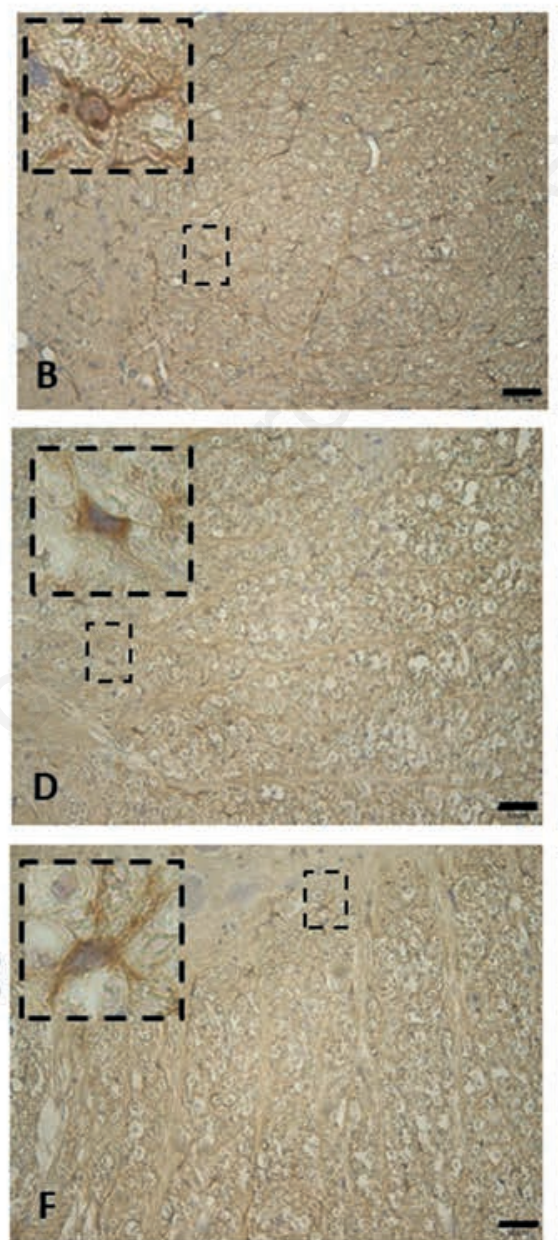
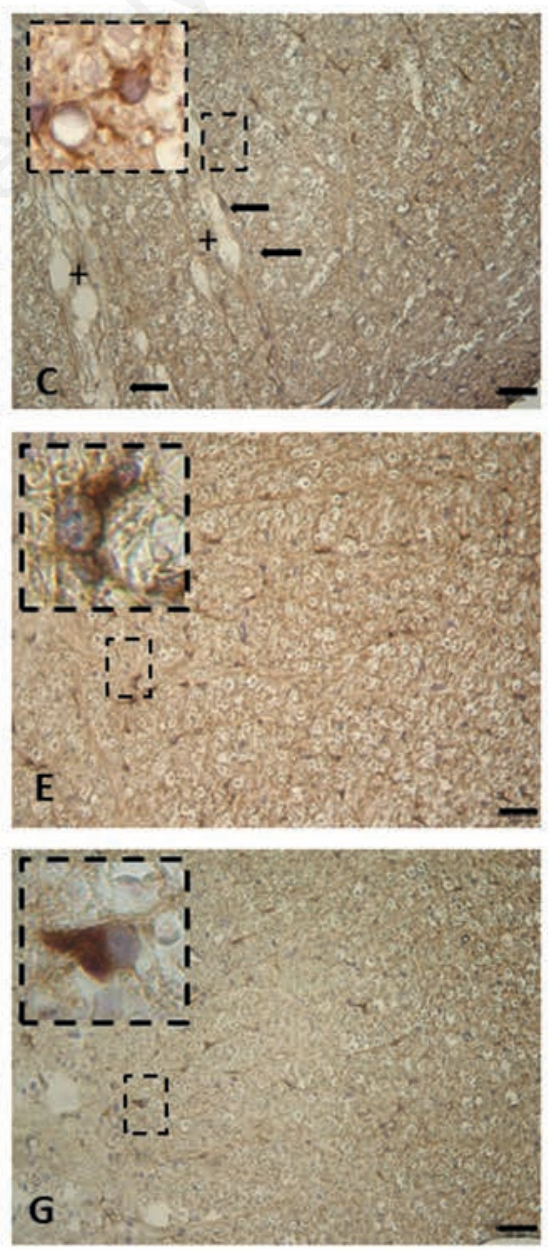

Figure 2. Microphotographs of GFAP positive astrocytes in the white matter of rabbit's spinal cord and statistical analysis of GFAP positive astrocytes. A) Sham control group 1, astrocytes have thin long processes with weaker GFAP positivity; scale bar: 20 mm. B) Ischemic group 2, astrocytes with thick GFAP positive processes. C) Ischemic group 3, GFAP positive astrocytes (arrows) are present near swollen axons $\left({ }^{+}\right)$. D,E) Br preconditioned groups 4 and 5, hypertrophic astrocytes. F,G) Nor preconditioned groups 6 and 7 , hypertrophic cell bodies and processes of astrocytes; scale bar: $50 \mu \mathrm{m}$. H) Significant increase in the number of GFAP positive astrocytes was observed in ischemic group $2\left({ }^{* *} \mathrm{P}<0.01\right)$, group 3 , and all preconditioned groups 4, 5, 6, 7 (***P<0.001) vs sham control group 1 . Significant increase $\left({ }^{++} \mathrm{P}<\mathbf{0 . 0 0 1}\right)$ in the number of GFAP positive astrocytes was observed in both $\mathrm{Br}$ and Nor preconditioned group 5 and 7 after $48 \mathrm{~h}$ of reperfusion $v$ ischemic group 3. In $\mathrm{Br}$ preconditioned groups $5 v s \quad 4(\bullet \mathrm{P}<0.05)$ and also in Nor preconditioned groups 7 vs $6(\circ \mathrm{P}<0.05)$ significant increase in the number of GFAP positive astrocytes was found. Data are expressed as mean \pm SEM; ANOVA and Tukey-Kramer test were used. 
in the ischemic group 3 after $48 \mathrm{~h}$ of reperfusion. The comparison among the ischemic group 3 vs preconditioned groups 5 and 7 showed statistically significant decrease of Mn-SOD activity. Pharmacological preconditioning showed time dependent decrease of Mn-SOD activity in the white matter. The significant decrease of Mn-SOD activity after $\mathrm{Br}$ or Nor preconditioning provided a protective mechanism against mitochondrial damage and caused remodulation of mechanisms for protective proteosynthesis leading to a switch from pro-apoptotic to anti-apoptotic pathway. ${ }^{2}$ It was also demonstrated that an application of $\mathrm{Br} 3$ and $6 \mathrm{~h}$ after focal brain ischemia prevented the release of Mn-SOD from the mitochondria. $^{27}$

According to our results, catalase activity was considerably increased only in the ischemic group 3 after 48 h of reperfusion, similarly, like it was present in the results of Mn-SOD level. The comparison among the ischemic group $3 v s$ preconditioned groups 5 and 7 showed statistically significant decrease of catalase activity. Decreased level of antioxidant enzyme catalase was confirmed in rabbit spinal cord ischemia. ${ }^{28}$ According to Ozen et al. ${ }^{29}$ catalase activity increases during oxidative stress. But if oxidative stress lasts a long time and overwhelms the capacity of catalase activity, catalase activity can be reduced.

The other possible explanation of antioxidant enzymes activation after ischemia reperfusion injury is the activity of the white matter glial cells: microglia and astrocytes. However, hypoxic condition in the white matter did not induce responses of oligodendrocytes, as well as no anti-oxidant responses..$^{30}$ Astrocytes are the most abundant subtypes of glial cells which provide many functions, including structural support, metabolism, maintenance of the extracellular environment, regulation of blood flow, stabilization of cell-cell communication and defence against oxidative stress. ${ }^{31}$ In the white matter fibrous astrocytes have physical contact with oligodendrocytes and play crucial role in support of the white matter. ${ }^{32}$ Activation of astrocytes is characterized by increased expression of the GFAP and vimentin. GFAP is a protein found in the cytoskeleton of astrocytes. ${ }^{33}$ GFAP is highly expressed in the white matter compared to the grey matter. ${ }^{34}$ In the present study, we demonstrate that $\mathrm{Br}$ or Nor preconditioning applied $48 \mathrm{~h}$ before $20 \mathrm{~min}$ of ischemia followed by 24 or $48 \mathrm{~h}$ of reperfusion influences GFAP immunoreaction in the astrocytes. Activated astrocytes were detected after $48 \mathrm{~h}$ of reperfusion at the border of the white and grey matter, and near the efferent axons radiating from anterior horns of the rabbit's spinal cord in both preconditioned groups 5 and 7. In both preconditioned groups was significant increase of GFAP positive astrocytes. Our results show that $\mathrm{Br}$ or Nor preconditioning leads to a marked increase of activated GFAP positive astrocytes in the spinal cord white matter after ischemia and $48 \mathrm{~h}$ of reperfusion. On the contrary, in the ischemic group $48 \mathrm{~h}$ of reperfusion leads to significant decrease of GFAP positive astrocytes. In the injured tis-
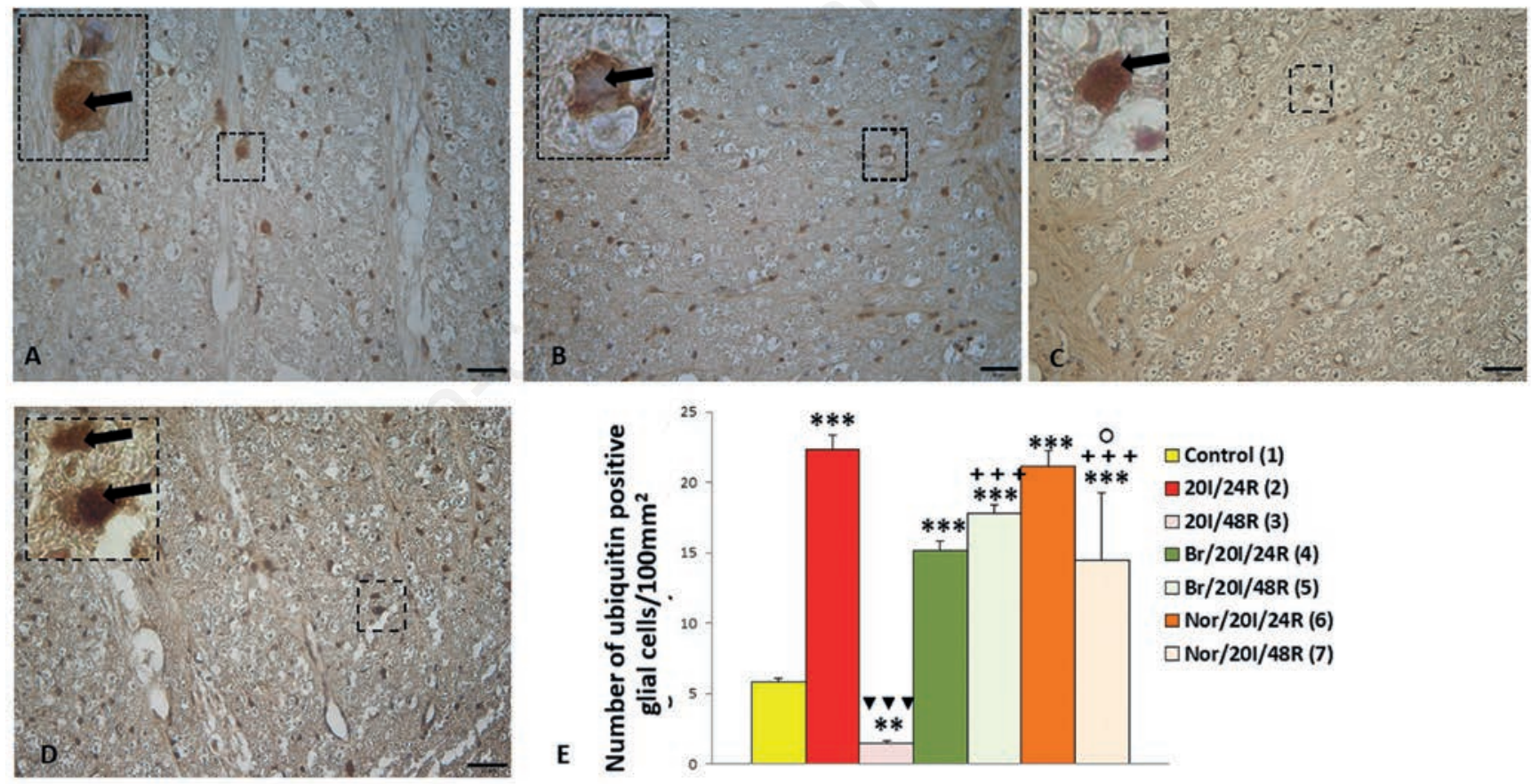

Figure 3. Microphotographs of ubiquitin distribution in the glial cells of rabbit's spinal cord white matter and statistical analysis of ubiquitin positive glial cells. A) Br preconditioned group 4, glial cells showed higher ubiquitin positivity in nuclei (arrow). B) Br preconditioned group 5, reduced nuclear ubiquitin positivity (arrow) present in glial cells. C) Ischemic group 2, dark brown aggregates of ubiquitin (arrow) in the cytoplasm of glial cells. D) Ischemic group 3, prominent dark brown aggregates of ubiquitin (arrows) was found; A-D) scale bar: $50 \mu \mathrm{m}$. E) Significant increase $(* * * \mathrm{P}<0.001)$ in the number of ubiquitin positive glial cells was observed in ischemic group 2, in both Br preconditioned groups 4,5 and both Nor preconditioned groups 6, 7 in comparison to sham control group 1. In ischemic group 3 after $48 \mathrm{~h}$ of reperfusion significant decrease $(* * \mathrm{P}<0.01)$ in the number of ubiquitin positive glial cells was present $v s$ sham control group 1 . Significant decrease $(\nabla \nabla \nabla \mathrm{P}<0.001)$ in the number of ubiquitin positive glial cells after $48 \mathrm{~h}$ of reperfusion was revealed in ischemic group $3 v$ ischemic group 2 with $24 \mathrm{~h}$ of reperfusion. In $\mathrm{Br}$ and Nor preconditioned groups 5 and 7 after $48 \mathrm{~h}$ of reperfusion significant increase $(+++\mathrm{P}<0.001)$ in the number of ubiquitin positive glial cells was found $v s$ ischemic group 3. Significant changes $(\circ \mathrm{P}<0.05)$ were also observed between $\mathrm{Br}$ and Nor preconditioned groups 5 and 7 after $48 \mathrm{~h}$ of reperfusion. Data are expressed as mean \pm SEM; ANOVA and Tukey-Kramer test were used. 
sue of the CNS astrocytes undergo important morphological modifications to form a glial scar, a physical and functional wall surrounding the damaged area. ${ }^{35}$ Ischemia and reperfusion activate astrocytes to produce many regulatory factors limiting tissue damage and restoring homeostasis..$^{36}$ Reactive astrogliosis is a multifactorial phenomenon after spinal cord injuries. Astrogliosis minimizes secondary tissue damage by restraining the lesion, providing growth factors, cytokines, restoring tissue structure, revascularization or removal of tissue debris from the injured area. ${ }^{37}$ Our findings suggest that $\mathrm{Br}$ or Nor preconditioning influence activation of astrocytes. Reactive astrocytes are one of the contributing factors in reducing of secondary tissue degeneration after $\mathrm{I} / \mathrm{R}$.

In our study we also focused on ubiquitin activation. In the white matter glial cells of $\mathrm{Br}$ preconditioned group 4 and Nor preconditioned group 6 the higher ubiquitin positivity was observed in the nuclei. However, lower immunoreaction was found in the cytoplasm. Both preconditioned groups 4 and 6 showed significant increase of ubiquitin positive glial cells in comparison with sham control group 1. Significant increase of ubiquitin positive glial cells was observed also in ischemic group $2 v s$ sham control group 1. On the contrary, in the ischemic group 2 distribution of ubiquitin positive aggregates in the cytoplasm of glial cells was prominent, but the nuclei lacked ubiquitin positivity. After $48 \mathrm{~h}$ of reperfusion significant decrease of ubiquitin positive cells was present in the ischemic group 3. Glial cells, which were present in the white matter of ischemic group 3 showed prominent dark ubiquitin aggregates in the cytoplasm. Ubiquitin aggregates are the signs of damaged, degenerated cells that have lost their ability of intracellular hydrolytic degradation of altered proteins. ${ }^{38}$ Glial cells are essential for proper neuronal function and adopt a reactive phenotype in the nerve tissue injury. The cells unable to synthesize new ubiquitin, appear to be those that succumb to the degenerative process. The level of altered proteins increases after ischemia. The elimination of those proteins is important for surviving of damaged cells. Ubiquitin is promptly synthesized in the cytoplasm and transduced to the nucleus where it mediates removal of denatured proteins and chromatin rearrangements. Ubiquitin can interact with DNA targeting proteins, like chromatin histone $\mathrm{H} 2 \mathrm{~B}$. This ubiquitin-chromatin interaction could mediate transcription of specific DNA regions. ${ }^{39,40}$ The upregulation of ubiquitin in the nucleus may mediate the stress response to ischemic injury by influencing the expression of other stress proteins such as heat shock proteins. ${ }^{41}$ Therefore, higher immunoreaction of ubiquitin in nuclei of white matter glial cells might play an important role. On the contrary, the lack of ubiquitin positivity in nuclei could be considered to be great disadvantage for glial cells in the white matter. ${ }^{42,43}$ Moreover, colocalization of CuZn-SOD and ubiquitinated-protein aggregates were found in astrocytes ${ }^{44}$ Our results indicate that Nor or $\mathrm{Br}$ preconditioning applied $48 \mathrm{~h}$ prior to 20 min of ischemia contributes to glial cells response after ischemia and reperfusion. We suppose that increase in free radical production during and after preconditioning may eventually activate the synthesis of stress proteins and antioxidant enzymes also in glial cells, which are essential for tissue protection from oxidative stress during reperfusion period. The pharmacological preconditioning could provide a novel strategy to make spinal cord white matter more resistant to oxidative stress by influencing of antioxidant enzyme levels and ubiquitin regulation of chromatin. Understanding of the exact mechanisms of preconditioning neuroprotective effects requires more studies to develop therapies that can exploit those endogenous protective pathways.

\section{References}

1. McDonough A, Weinstein JR. Neuroimmune Response in Ischemic Preconditioning. Neurotherap 2016; 748-61.

2. Sugino T, Nozaki K, Takagi Y, Hashimoto N. 3-Nitropropionic acid induces ischemic tolerance in gerbil hippocampus in vivo. Neurosci Lett 1999;259:9-12.

3. Puisieux F, Deplanque D, Pu Q, Souil E, Bastide M, Bordet R. Differential role of nitric oxide pathway and heat shock protein in preconditioning and lipopolysaccharide-induced brain ischemic tolerance. Eur $\mathrm{J}$ Pharmacol 2000;389:71-8.

4. Ravingerova T, Pancza D, Ziegelhoffer A, Styk J. Preconditioning modulates susceptibility to ischemia-induced arrhythmias in the rat heart: the role of alpha-adrenergic stimulation and K(ATP) channels. Physiol Res 2002;51:109-19.

5. Mechírová E, Danielisová V, Domoráková I, Danková M, Stebnický M, Mičková $H$, et al. Bradykinin preconditioning affects the number of degenerated neurons and the level of antioxidant enzymes in spinal cord ischemia in rabbits. Acta Histochem 2014;116:252-57.

6. Matute C. Domercq M, Pérez-Samartin
A, Ransom BR. Protecting white matter from stroke injury. Stroke 2013;44: 1204-11.

7. Goursad S, Kozlova EN, Maloteaux JM, Hermans E. Cultured astrocytes derived from corpus callosum or cortical grey matter show distinct glutamate handling properties. J Neurochem 2009; 108:1442-52.

8. Hassel B, Boldingh KA, Narvesen C, Iversen EG, Skrede KK. Glutamate transport, glutamine synthetase and phosphate-activated glutaminase in rat CNS white matter. A quantitative study. J Neurochem 2003;87:230-37.

9. Suzuki T, Motohashi H, Yamamoto M. Toward clinical application of the Keap1-Nrf2 pathway. Trends Pharmacol Sci 2013;34:340-46.

10. Huang L, Wu ZB, Zhuge Q, Zheng W, Shao B, Wang B, et al. Glial scar formation occurs in the human brain after ischemic stroke. Int J Med Sci 2014;11: 344-8.

11. Danielisová V, Nemethová $\mathrm{M}$, Gottlieb M, Burda J. Activities of endogenous antioxidant enzymes in the cerebrospinal fluid and hippocampus after transient forebrain ischemia in rat. $\mathrm{J}$ Neurol Sci 2007;253:61-5.

12. Miao L, St. Clair DK. Regulation of Superoxide Dismutase Genes: Implications in Diseases. Free Radic Biol Med 2009;47:344-56.

13. Sainz IM, Pixley RA, Colman RW. Fifty years of research on the plasma kallikrein-kinin system: from protein structure and function to cell biology and in vivo pathophysiology. Thromb Haemost 2007;98:77-83.

14. Dong R, Xu X, Li G, Feng W, Zhao G, Zhao J, et al. Bradykinin inhibits oxidative stress-induced cardiomyocytes senescence via regulating redox state. Plos One 2013;8:77034.

15. Danielisová V, Gottlieb M. Némethová M, Burda J. Effects of bradykinin postconditioning on endogenous antioxidant enzyme activity after transient forebrain ischemia in rat. Neurochem Res 2008;33:1057-64.

16. Danielisová V, Gottlieb M, Némethová M, Kravčuková P, Domoráková I, Mechírová E, et al. Bradykinin postconditioning protects pyramidal CA1 neurons against delayed neuronal death in rat hippocampus. Cell Mol Neurobiol 2009;29:871-78.

17. Gross J, Baker E, Moore J, Falck J, Nithipatikom K. Abdominal surgical incision induces Remote Preconditioning of Trauma (RPCT) via activation of Bradykinin Receptors (BK2R) and the cytochrome P450 epoxygenase pathway in canine hearts. Cardiovasc Drugs Ther 
2011;25:517-22.

18. Saxena P, Aggarwal S, Misso N, Passage J, Newman M, Thompson P, et al. RIPC downregulates kinin receptor expression in neutrophils of patients undergoing heart surgery. Interact Cardiovasc Thorac Surg 2013;17:653-8.

19. Danielisová V, Nemethová M, Gottlieb M, Burda J. Changes of endogenous antioxidant enzymes during ischemic tolerance acquisition. Neurochem Res 2005;30:559-65.

20. Burda J, Matiašová M, Gottlieb M, Danielisová V, Némethová M, Garcia L, et al. Evidence for role of second Pathophysiological stress in prevention of delayed neuronal death in the hippocampal CA1region. Neurochem Res 2005;30:1397-405.

21. Zivin JA, De Girolami U. Spinal cord infarction: a highly reproducible stroke model. Stroke1980;11:200-2.

22. Sun Y, Oberley LW, Li Y. A simple method for clinical assay of super-oxide dismutase. Clin Chem 1988;34:497500 .

23. Goth LA. Simple method for determination of catalase activity and revision of reference range. Clin Chim Acta 1991;14:143-51.

24. Jansen AHP, Reits EAJ, Hol EM. The ubiquitin proteasome system in glia and its role in neurodegenerative diseases. Front Molec Neurosci 2014;7:1-14.

25. Ikinci A, Mercantepe T, Unal D, Erol HS, Sahin A, Aslan A. Morphological and antioxidant impairments in the spinal cord of male offspring rats following exposure to a continuous 900 $\mathrm{MHz}$ electromagnetic field during early and mid-adolescence. J Chem Neuroanat 2016;75:99-104.

26. Burda J, Danielisová V, Nemethová M, Gottlieb M, Matiasová M, Domoráková $\mathrm{I}$, et al. Delayed postconditionig initiates additive mechanism necessary for survival of selectively vulnerable neurons after transient ischemia in rat brain. Cell
Mol Neurobiol 2006;26:1141-51.

27. Danielisova V, Gottlieb M, Bonova P, Nemethova M, Burda J. Bradykinin postconditioning ameliorates focal cerebral ischemia. Neurochem Internat 2014;72:22-9.

28. Ilhan A, Koltuksuzb U, Ozenc S, Uzd E, Ciralikc H, Akyold O. The effects of caffeic acid phenethyl ester (CAPE) on spinal cord ischemia/reperfusion injury in rabbits. Cardiothorac Surg 1999; 16:458-63.

29. Ozen OA, Cosar M, Sahin O, Fidan H, Eser O, Mollaoglu H, et al. The protective effect of fish n-3 fatty acids on cerebral ischemia in rat prefrontal cortex. Neurol Sci 2008;29:147-52.

30. Marrif H, Juurlink BHJ. Differential vulnerability of oligodendrocytes and astrocytes to hypoxic-ischemic stresses. Adv Mol Cell Biol 2003;31:857-67.

31. Ransom BR, Ransom CB. Astrocytes: Multitalented stars of the central nervous system. Methods Mol Biol 2012;814:3-7.

32. Lundgaard I, Osório MJ, Kress B, Sanggaard S, Nedergaard M. White matter astrocytes in health and disease. Neurosci 2014;276:161-73.

33. Yokobori S, Zhang Z, Moghieb A, Mondello S, Gajavelli S, Dietrich WD, et al. Acute Diagnostic Biomarkers for Spinal Cord Injury. World Neurosur 2015;83:867-78.

34. Goursaud S, Kozlova EN, Maloteaux JM, Hermans E. Cultured astrocytes derived from corpus callosum or cortical grey matter show distinct glutamate handling properties. J Neurochem 2009;108:1442-52.

35. Pekny M, Pekna M, Messing A, Steinhauser C, Lee JM, Parpura V, et al. Astrocytes: a central element in neurological diseases. Acta Neuropathol 2016;31:323-45.

36. Choi SS, Lee HJ, Lim I, Satoh JI, Kim SU. Human Astrocytes: Secretome Profiles of Cytokines and Chemokines.
Plos One 2014;9:923-5.

37. Bylicky MA, Meller GP, Day RM. Mechanism of Endogenous Neuroprotective Effects of Astrocytes in Brain Injury. Oxi Med Cell Long 2018;ID6501031:1-16.

38. Mechírová E, Feriková M, Domoráková I. Extract EGb 761 pretreatment limits ubiquitin positive aggregates in rabbit spinal cord neurons after ischemia/ reperfusion. Cell Mol Neurobiol 2006;26:1443-52.

39. Risuleo G, Cristofanilli M, Scarsella G. Acute ischemia/reperfusion in rat hippocampal neurons activates nuclear ubiquitin and alters both chromatin and DNA. Mol Cell Biochem 2003;250:7380.

40. Mengual E, Arizti P, Rodrigo J, Giménez-Amaya JM, Castano JG. Immunohistochemical Distribution and Electron Microscopic Subcellular Localization of the Proteasome in the Rat CNS. J Neurosci1996;16:6331-41.

41. Yamauchi T, Sakurai, M, Abe K, Matsumiya G, Sawa Y. UbiquitinMediated Stress Response in the Spinal Cord After Transient Ischemia. Stroke 2008;39:1883-9.

42. Giffard RG, Xu L, Zhao H, Carrico W, OuyangY, Qiao Y, et al. Chaperones, protein aggregation, and brain protection from hypoxic/ischemic injury. J Exp Biol 2004;207:3213-20.

43. Noor NM, Møllgård K, Wheaton BJ, Steer DL, Truettner JS, Dziegielewska $\mathrm{KM}$, et al. Expression and cellular distribution of ubiquitin in response to injury in the developing spinal cord of Monodelphis domestica. Plos One 2013;8:1-15.

44. Chen X, Guan T, Li L, Shang H, Cui L, Li XM, et al. SOD1 aggregation in astrocytes following ischemia/reperfusion injury: a role of NO-mediated S-nitrosylation of protein disulfide isomerase (PDI). J Neuroinflam 2012;9:1-12. 